\title{
Carla Fratta (dir.), Littérature et cinéma au Québec
} 1995-2005

\section{Francesca Torchi}

\section{(2) OpenEdition}

\section{Journals}

\section{Edizione digitale}

URL: http://journals.openedition.org/studifrancesi/7759

DOI: 10.4000/studifrancesi.7759

ISSN: 2421-5856

\section{Editore}

Rosenberg \& Sellier

\section{Edizione cartacea}

Data di pubblicazione: 1 décembre 2009

Paginazione: 682-683

ISSN: 0039-2944

\section{Notizia bibliografica digitale}

Francesca Torchi, «Carla Fratta (dir.), Littérature et cinéma au Québec 1995-2005», Studi Francesi [Online], 159 (LIII | III) | 2009, online dal 30 novembre 2015, consultato il 09 janvier 2021. URL: http:// journals.openedition.org/studifrancesi/7759; DOI: https://doi.org/10.4000/studifrancesi.7759

Questo documento è stato generato automaticamente il 9 janvier 2021.

\section{(c) $(7)$}

Studi Francesi è distribuita con Licenza Creative Commons Attribuzione - Non commerciale - Non opere derivate 4.0 Internazionale. 


\title{
Carla Fratta (dir.), Littérature et cinéma au Québec 1995-2005
}

\author{
Francesca Torchi
}

\section{NOTIZIA}

CARLA FRATTA (dir.), Littérature et cinéma au Québec 1995-2005, avec la collaboration de J.-F. PLAMONDON, Bologna, Pendragon, 2008. pp. 148.

Littérature et cinéma au Québec 1995-2005 costituisce il punto d'intersezione tra due differenti direzioni di ricerca relative al rapporto tra il testo letterario e la sua trasposizione cinematografica in Canada. Esso raccoglie infatti i contributi francofoni su cinema e letteratura in Québec presentati nel contesto più ampio del Convegno Littérature et Cinéma au Canada. Cultures en comparaison 1995-2005/Literature and Cinema in Canada. Comparing Cultures 1995-2005, organizzato a Bologna (6-12 dicembre 2006) dal Centro Interuniversitario di Studi Quebecchesi e dal Centro di Studi Canadesi. Il volume si propone come la naturale prosecuzione di una ricerca realizzata nel 1995 sullo stesso argomento riguardante il decennio precedente. Come esplicita la curatrice nell'AvantPropos, questa operazione ha il preciso intento di «assurer l'extension de la recherche à la décennie suivante, soulignant ainsi la continuité d'une entreprise et en même temps la vitalité d'une institution» (p. 7). Ognuno dei dieci saggi intende rendere conto di un punto di vista differente sull'argomento, così che il volume risulta offrire nel suo insieme una riflessione estremamente sfaccettata «sur les problèmes de l'adaptation d'un media à un autre, afin d'encadrer et d'éclairer le discours dans son ensemble» (p. 7). In apertura Un art de l'emprunt. Les sources intermédiales de l'adaptation di André GAUDREAULT e Philippe MARION, svolge la funzione di introduzione teorica e, insieme, di filo conduttore dell'intera ricerca. Sottolineando come il lavoro di adattamento di un testo letterario al cinema sia riconducibile a una pratica intertestuale, vengono in particolare evidenziati gli aspetti che determinano il passaggio da un sistema semiotico all'altro. A questo saggio seguono due testimonianze: Garder mes distances del 
romanziere François BARCELO, e Le Théâtre au cinéma ou le dramaturge devient scénariste! di Michel Marc BOUCHARD. Barcelo racconta - e romanza - la propria esperienza di scrittore nel momento in cui si è trovato personalmente coinvolto nel processo di trasposizione cinematografica dei propri romanzi (il solo che avrà un destino anche cinematografico sarà Cadavres). Con una scrittura vivace e ironica, Barcelo afferma di privilegiare, in questo processo, la prospettiva dello spettatore, così come dichiara una preferenza esclusiva per l'attività di scrittore e non di sceneggiatore di se stesso. Una posizione assai diversa è quella di Bouchard, che è anche sceneggiatore di un film tratto dalla sua pièce Les Feleuettes , e si rivela interessato, da un punto di vista creativo, a questo tipo di lavoro sul testo: un'operazione forse di compromesso ma anche di grande apertura. Marie Frédérique DESBIENS, in Entre le didactique et le romantique. Les représentations des Patriotes dans "Quand je serai parti... vous vivrez encore" de Michel Brault et "15 février 1839" de Pierre Falardeau, mette a confronto due film sulla Ribellione dei Patrioti e, attraverso un'analisi contrastiva, individua e riconosce uno dei topoi fondamentali di tutta una letteratura quebecchese: il Patriota come uomo del popolo. Il contributo Portraits littéraires à l'écran: Anne Hébert et Marie-Claire Blais di Anne DE VAUCHER si concentra invece sul genere filmico del ritratto letterario attraverso i documentari sulle scrittrici quebecchesi Anne Hébert e Marie-Claire Blais. La sua riflessione mette a fuoco due documentari: quello di Suzette Lagacé sulla vita e l'opera di Marie-Claire Blais e quello firmato dallo scrittore Jacques Godbout su Anne Hébert. In questo secondo caso il prodotto filmico si rivela il luogo di incontro e di dialogo tra i due scrittori quebecchesi (Godbout e la Hébert). Insieme, l'uno nelle vesti di regista, l'altra di protagonista, promuovono la letteratura di cui fanno parte per affermarne i caratteri e sostenerne la diffusione.

2 André LOISELLE in Horreur et dépaysement. L'alterité géographique et médiatique comme source de terreur dans trois adaptations cinématographiques de roman d'épouvante québécois riflette, attraverso l'analisi incrociata di tre film, sul ruolo del cinema dell'orrore come «terrain fertile pour l'adaptation et en même temps comme une manière originale d'explorer, et de faire explorer au spectateur, l'imaginaire canadien-français» (p. 10). In L'adaptation cinématographique québécoise depuis Séraphin, un homme et son péché: résurgence d'un phénomène cyclique ou exploration de nouvelles voies?, Josiane OUELLET propone invece $\mathrm{i}$ risultati di una ricerca personale sul fenomeno della trasposizione e, passando in rassegna un ricco e dettagliato repertorio, mette in luce il progressivo incremento di questo genere di operazione non solo in ambito cinematografico ma anche televisivo. Con La vie et l'œuvre du peintre canadien René Richard adaptés à l'écran: le passage du réel à la médiatisation narrative, Esther PELLETIER descrive la propria esperienza di sceneggiatrice e di regista nel caso dell'adattamento «sur le mode cinématographique» che rappresenta la vita e l'opera del pittore canadese (e parente stretto) René Richard, di cui offre una personalissima ed affettiva interpretazione. Jean François PLAMONDON, nel saggio Parcours du littéraire dans "Les invasions barbares" di Denys Arcand, fornisce del film una lettura che ruota attorno all'accezione dell'aggettivo barbaro, prendendo lo spunto dalle riflessioni dello scrittore italiano Alessandro Baricco nel romanzo I Barbari. Ne emerge una visione generale della postmodernità come età barbara, quella in cui viene esplicitata la messa in scena artistica di una data cultura - nel caso specifico del film di Arcand, quella quebecchese. Il volume si chiude con il saggio La mémoire et le mythe des derniers hommes: "Atanarjuat" de Zacharias Kunuk di Alberto MANGUEL sul film Atanarjuat di Zacharias Kunuk, considerato una sorta di «lecture critique de l'Occident comme 
interprète des cultures inuit» (p. 11). L'ottica proposta saggio dopo saggio invita il lettore a considerare nella loro molteplicità i rapporti possibili tra cinema e letteratura quebecchesi, mettendo in luce la centralità e la fecondità del discorso metaletterario nella produzione contemporanea. 